\title{
Textos cognitivamente accesibles: Lectura fácil y Leichte Sprache en contraste ${ }^{1}$ Cognitively accessible texts: Lectura fácil and Leichte
Sprache in contrast
}

Ana Medina Reguera

Universidad Pablo de Olavide

anamedina@upo.es

https://orcid.org/0000-0002-3089-9745
Patricia Balaguer Girón

Universidad Pablo de Olavide

pbalgir@upo.es

https://orcid.org/0000-0002-7645-7045

Recibido: 07/12/2021

Aceptado: 31/12/2021

DOl: https://dx.doi.org/10.12795/mAGAzin.2021.i29.05

\section{Resumen:}

El objetivo de este estudio es ofrecer un análisis contrastivo alemán-español de una modalidad de traducción que viene desarrollándose con cada vez más frecuencia en el marco de la comunicación accesible. Aunque desde otros ámbitos se denomina «método de redacción o de adaptación" (IFLA 2010, AENOR 2018), en este trabajo se defiende la inclusión de la lectura fácil (Easy-to-Read, en inglés, y Leichte Sprache, en alemán) como una modalidad de traducción intralingüística e intersemiótica de un texto estándar a un texto fácilmente legible y comprensible. Se compara el desarrollo desde el inicio de esta práctica en Alemania y en España y se cotejan los conjuntos de pautas o normativas disponibles, la cobertura legal de la lectura fácil en ambos países y algunas de sus características lingüísticas. Finalmente, se establecen unas comparaciones globales.

Palabras clave: lectura fácil, lengua fácil, lingüística contrastiva, variedad lingüística, accesibilidad lingüística, traducción accesible

\begin{abstract}
:
The aim of this study is to offer a German-Spanish contrastive analysis of a translation modality that is increasingly being developed in the context of accessible communication. Although in other fields it is referred to as an 'edit or adaptation method' (IFLA 2010, UNE 2018), this paper argues for the inclusion of easy-to-read (Easy-to-Read, in English, and Leichte Sprache, in German) as a form of intralinguistic and intersemiotic translation of a standard text into an easily legible and comprehensible text. This work compares the development since the beginning of this practice in Germany and Spain, as well as the sets of guidelines or regulations available, the legislative coverage of easyto-read, some of its linguistic features and some final comparisons.
\end{abstract}

Keywords: Easy-to-Read, easy language, contrastive linguistics, linguistic variety, linguistic accessibility, accessible translation 


\section{Introducción}

El objetivo de este estudio es ofrecer un análisis contrastivo alemán-español de una modalidad de traducción que viene desarrollándose con cada vez más frecuencia en el marco de la comunicación accesible. Aunque desde otros ámbitos se denomina método de redacción o de adaptación (IFLA 2010, AENOR 2018), en este trabajo se defiende la inclusión de la lectura fácil (Easy-to-Read, en inglés, y Leichte Sprache, en alemán) como una modalidad de traducción intralingüística e intersemiótica de un texto estándar a un texto fácilmente legible y comprensible. Con texto estándar nos referimos a textos, no necesariamente especializados, de cualquier género; con textos fácilmente legibles y comprensibles aludimos a textos expresamente elaborados para personas con dificultades de comprensión lectora. Se trata de una modalidad de traducción intralingüística porque el texto origen (TO) está en la misma lengua que el texto meta (TM), aunque también sería posible la traducción interlingüística de un TO estándar en una lengua A a un TM en lectura fácil en una lengua $\mathrm{B}$, o bien de un $\mathrm{TO}$ en lectura fácil en una lengua $\mathrm{A}$ a otro texto en lectura fácil en una lengua B. Por último, la traducción es intersemiótica porque los textos en lectura fácil son multimodales, esto es, se componen de texto, ilustración y elementos paratextuales, independientemente de si los textos originales contienen imágenes o no.

Los destinatarios de la lectura fácil no configuran un grupo homogéneo. A diferencia de otras modalidades de accesibilidad lingüística, como el subtitulado o la audiodescripción, la lectura fácil se erige desde sus inicios como una herramienta transversal. Los receptores suelen describirse en los textos en español como personas con dificultades de comprensión lectora, mientras que en alemán es frecuente el término personas con dificultades de aprendizaje (Menschen mit Lernschwierigkeiten). Según qué normativa se consulte, la lectura fácil se debe dirigir a las personas con discapacidad intelectual (aunque otros colectivos se beneficien), o bien la lectura fácil se dirige a varios grupos por igual. Entre los destinatarios que podríamos considerar indirectos o secundarios, se encuentran las personas con problemas mentales, las personas sordas, las personas mayores, las personas con afasias, las personas con dislexia, las personas con bajo nivel de alfabetización por motivos socioeconómicos o incluso por desconocimiento del idioma e incluso los niños de la escuela primaria (IFLA 2010: 5-9; AENOR 2018: 7-8). Por otro lado, en la práctica de la traducción a lectura fácil, los destinatarios de los textos se sitúan también, además de como público objetivo, como parte del proceso de revisión traductora, pues, como veremos, el encargo de traducción no se entrega al cliente hasta que no ha sido validado por, al menos, una persona con problemas de comprensión lectora. En cuanto a su situación o relación dentro de los Estudios de Traducción, la lectura fácil se ubica junto a otras modalidades de traducción accesible como la audiodescripción o el subtitulado para sordos.

En los siguientes apartados abordamos el concepto de lectura fácil en España y de Leichte Sprache en Alemania, seguidos de una reseña histórica sobre el desarrollo de la lectura fácil en ambos países, además del respaldo jurídico y las diferencias y similitudes de cómo está practicándose la lectura fácil en Alemania y en España. A pesar de que la lectura fácil también tiene un papel importante en Austria y en Suiza, nos centraremos en Alemania. Para el español, por su parte, hemos acotado el análisis a España.

\section{Conceptualización: Ia lectura fácil en el marco de la accesibilidad cognitiva}

La discapacidad es un concepto que ha evolucionado desde una visión negativa basada en la segregación hasta un modelo social basado en los derechos humanos. En la Clasificación Internacional del Funcionamiento, de la Discapacidad y de la Salud (CIF), que ha sido desarrollada por la Organización Mundial de Salud como entidad supranacional de referencia, se subraya que la discapacidad es una relación social y que depende de 
la interacción entre los factores ambientales, sociales y personales. ${ }^{2}$ Esto es, las personas con discapacidad necesitan ver satisfechas sus necesidades con la misma importancia que el resto de personas, por lo que deben garantizarse sus derechos con base en la igualdad de oportunidades, la eliminación de barreras y obstáculos para su participación, la accesibilidad y el diseño universal, la no discriminación y la inclusión en todos los ámbitos de la vida.

Según la OMS, la discapacidad afecta a un quince por ciento de la población mundial ${ }^{3}$ y puede ser permanente o temporal, además de un fenómeno en ascenso, debido al envejecimiento de la población y a la prevalencia de las enfermedades crónicas. En materia de accesibilidad, la accesibilidad cognitiva (Larraz Istúriz 2015) se encuentra, aunque solo implícitamente, en los textos legislativos sobre accesibilidad universal, en tanto que esta se define como la capacidad de los productos, servicios y entornos para ser usables, comprensibles y practicables por todas las personas, independientemente de su condición, según el art. 9 de la Convención sobre los Derechos de las Personas con Discapacidad ${ }^{4}$ y otros textos legislativos nacionales en los diferentes estados que la han ratificado. ${ }^{5}$

Por tanto, la lectura fácil forma parte de una estrategia global, cuyo objetivo es facilitar la accesibilidad cognitiva, que se consolida como un tipo más de accesibilidad -junto a la accesibilidad arquitectónica y sensorial- eliminando las barreras en la comprensión, interacción y uso de productos y servicios en diferentes entornos, contribuyendo a la accesibilidad universal, al diseño para todos y a la igualdad de oportunidades en la participación (AENOR $1531012018:$ 1).

La accesibilidad cognitiva implica que las personas entiendan los entornos y sean capaces de interactuar y usarlos de manera correcta. En la definición de Belinchón et al. (2014: 11), la accesibilidad cognitiva es «la propiedad que tienen aquellos entornos, procesos, bienes, productos, servicios, objetos o instrumentos, herramientas y dispositivos que resultan inteligibles o de fácil comprensión». Las personas deben entender el significado de los entornos y objetos, o sea, entender cómo, a qué clase y categoría pertenecen, para qué y cómo se usan, cuál es su interpretación sociocultural, si existe relación entre esos objetos y entre otros objetos y entornos. En este contexto conceptual, la lectura fácil es solo uno de los instrumentos posibles. Según el informe sobre la Accesibilidad Cognitiva en España, del Observatorio estatal de la discapacidad ${ }^{6}$ de 2016, otros recursos son el Wayfinding (orientación en el espacio, uso de señales y líneas en el suelo, uso de colores en arquitectura), los pictogramas y las señales, entre otros.

Las capacidades cognitivas se refieren al procesamiento de la información: la atención, la percepción, la memoria, la resolución de problemas o la comprensión. La organización estadounidense para personas con discapacidad intelectual The $\operatorname{Arc}^{7}$ enumera, para que la información sea accesible, una serie de requisitos necesarios en el proceso comunicativo: minimizar el uso de la memoria, uso de variados formatos y tantos como sea posible (visual, audio, multi gráfico), no tener que utilizar una habilidad organizativa compleja, y vocabulario o nivel de lectura adecuado a la capacidad comprensiva. Desde esta perspectiva, la lectura fácil trata de ser un producto de apoyo o una herramienta para suplir las carencias de algunas personas en el proceso cognitivo lector.

En este sentido, la lectura fácil es un producto de apoyo de entre los recogidos en la ISO 9999:2016 Productos de apoyo para personas con discapacidad. Clasificación y terminología, adaptado primero como norma europea

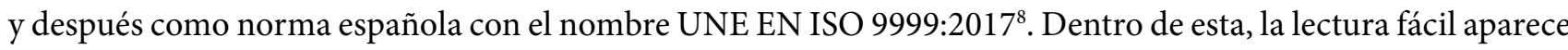
bajo los códigos 051506 (Productos de apoyo para la codificación y decodificación del lenguaje escrito) y 050306 (Materiales de entrenamiento/aprendizaje para desarrollar la capacidad lectora). Este hecho también aparece recogido en la Norma Experimental UNE 153101 EX: Lectura Fácil. Pautas y recomendaciones para la elaboración de documentos (AENOR 2018), en la que la lectura fácil se define como un «método que recoge un conjunto de pautas y recomendaciones relativas a la redacción de textos, al diseño y maquetación de documentos y a la validación de la comprensibilidad de los mismos, destinado a hacer accesible la información a las personas con dificultades de comprensión lectora. (...) Los materiales resultantes de la aplicación del método pueden

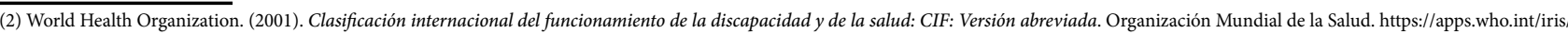
handle/10665/43360

(3) https://www.who.int/news-room/fact-sheets/detail/disability-and-health

(4) Texto íntegro de la Convención sobre los Derechos de las Personas con Discapacidad disponible en https://www.un.org/esa/socdev/enable/documents/tccconvs.pdf

(5) España ratificó la Convención en 2007 y Alemania en 2009.

(6) Documento disponible en https://www.observatoriodeladiscapacidad.info/wp-content/uploads/La-accesibilidad-cognitiva.pd

(7) The Arc (organización estadounidense de personas con discapacidad intelectual: https://thearc.org/ )

(8) Véase ISO - ISO 9999:2016 - Assistive products for persons with disability - Classification and terminology (https://www.iso.org/standard/60547.html) y UNE-EN ISO 9999:2017 Productos de apoyo para personas con discapacidad (https://www.aenor.com/normas-y-libros/buscador-de-normas/une?c=N0058322 ) respectivamente. 
considerarse productos de apoyo para personas con dificultades de comprensión lectora» (2018:7).

\section{El origen de la lectura fácil}

El término lectura fácil es una traducción al español de Easy-to-Read, pero los orígenes de la lectura fácil se sitúan en Suecia y se asume que el primer libro adaptado y señalizado como lectura fácil (lättläst) se publicó en Suecia en 1968 por el Swedish National Board for Education (Sommaren med Monika, de Per Anders Fogelström). El término fue posteriormente acuñado y difundido por la organización internacional Inclusion Europe (Asociación europea de personas con discapacidad y sus familias), con sede en Bruselas y fundada en 1988 bajo el auspicio de la UE, así como por la Federación Internacional de Asociaciones e Instituciones Bibliotecarias (International Federation of Library Associations and Institutions, IFLA). La IFLA encargó a Ingemar Tronbacke de la Easy-to-read Foundation de Suecia (Centrum för Lättläst), la elaboración de directrices para materiales en Lectura Fácil. Por consiguiente, aunque como práctica tiene su origen en los años 60, no se expandió por el resto de los países del entorno hasta los noventa.

En 1988 se constituye la asociación europea International League of Societies for the Mentally Handicapped - European Association, que cambió su denominación a Inclusion Europe en el año 2000. En la constitución de esta asociación participan varios países, entre los que se encuentran representantes de asociaciones de personas con discapacidad intelectual tanto de Alemania como de España. En el seno de esta asociación se crearon las primeras directrices para generar información en lectura fácil en 1998 y en 2002 se diseña un logotipo azul con un libro y una mano cerrada con el pulgar hacia arriba para marcar que un texto está redactado o traducido a lectura fácil. ${ }^{9}$

Este logotipo tiene licencia creative commons pero exige unas instrucciones ${ }^{10}$ para su uso: Se puede usar siempre que se hayan respetado las guías Information for all (2010); haya sido revisado por, al menos, una persona con discapacidad intelectual; y se añada, junto al logotipo el siguiente copyright: «@ European Easyto-Read Logo: Inclusion Europe. More information at www.inclusion-europe.eu/easy-to-read». Estas guías de Información para todos fueron traducidas a quince lenguas ${ }^{11} \mathrm{y}$ se elaboraron en el marco del proyecto europeo Pathways. Su subítulo indica «estándares europeos para hacer la información fácil de leer y de comprender» (traducción propia de European standards for making information easy to read and understand).

A partir de estos dos documentos (las guías de la IFLA, por un lado y de Inclusion Europe, por otro) y sus traducciones, el desarrollo de los diferentes países dentro y fuera de la Unión Europea ha sido diferente. A continuación, vemos, de forma pormenorizada, el recorrido de la lectura fácil en España y en Alemania.

\section{Lectura fácil y Leichte Sprache: un recorrido histórico paralelo}

\subsection{El desarrollo de la lectura fácil en España}

En general, puede decirse que hay dos grandes centros impulsores de la lectura fácil en España: la Asociación de Lectura Fácil (ALF), por un lado, y Plena Inclusión (antes FEAPS), por otro. Desde ambos se ha extendido a todas las comunidades autónomas, tanto mediante la Red de Lectura Fácil (asociaciones ligadas a la ALF), como mediante las asociaciones que forman parte de Plena Inclusión. Además, Plena Inclusión España coordina la Red de Accesibilidad Cognitiva de Plena Inclusión, formada por expertos en accesibilidad cognitiva de las 17 federaciones autonómicas, Ceuta y Melilla.

Los comienzos de la lectura fácil en España se sitúan en 1998 con el encargo de la Fundación Jaume Bofill a Carme Mayol y a Eugenia Salvador de un estudio «sobre las posibilidades del libro fácil en Cataluña» ${ }^{12}$, así como con la traducción al catalán de las directrices de la IFLA. Posteriormente, en 2001, la comisión catalana registra su propio logotipo ${ }^{13}$, cuyo uso en la portada o contraportada de documentos y libros, como veremos más abajo, sigue un proceso de adaptación diferente. Seguidamente, en 2002, publica el primer libro en catalán No estem mai sols: conèixer Miquel Martí i Pol, de Publicacions de l'Abadia de Montserrat. En 2003 se constituyen oficialmente en asociación y organizan sus primeras Jornadas Internacionales sobre lectura fácil en 2005.

(9) Véase la web de Inclusion Europe, información disponible en https://www.inclusion-europe.eu

(10) Instrucciones para el uso del logotipo en https://www.inclusion-europe.eu/wp-content/uploads/2021/02/How-to-use-ETR-logo..pdf

(11) Disponible en https://www.inclusion-europe.eu/easy-to-read-standards-guidelines/

(12) Fuente en la web de la Asociación de Lectura Fácil: https://www.lecturafacil.net/es/info/cronologia/

(12) Fuente en la web de la Asociación de Lectura Fácil: https
(13) Véase logotipo en la web https://www.lecturafacil.net 
También en 2005 el grupo DILES (Discurso y lengua española) de la Universidad Autónoma de Madrid edita Don Quijote de la Mancha en lectura fácil ${ }^{14}$ y publica un trabajo (Anula Rebollo et al. 2006) sobre la argumentación lingüística de la adaptación, quizás el más elaborado desde un punto de vista lingüisticodescriptivo hasta el momento actual. El grupo DILES aborda la lectura fácil desde el concepto de mediación lingüística (textual y conceptual) y desde el español accesible, que se define como «una variedad lingüística optimizada para personas con dificultades de acceso a la información, particularmente escrita, por causa cognitivas, culturales, económico-sociales, personales, etc.» (Anula Rebollo, 2021)..$^{15}$

Desde el año 2009, España participó en los proyectos Pathways I y Pathways II, en los que se empezaron a confeccionar las reglas europeas para hacer información fácil de leer y comprender. A partir de esos proyectos, en los que participaron asociaciones de personas con discapacidad intelectual o del desarrollo, se promovió la incorporación de la figura del validador en el proceso de elaboración de documentos, haciendo uso de la premisa del movimiento de vida independiente «nada para nosotros sin nosotros». Los validadores son personas con discapacidad intelectual que revisan el texto meta final, no en función de si la traducción es correcta respecto del TO, al que no suelen tener acceso, sino en función del grado de a) adecuación a las normas de lectura fácil y b) legibilidad y comprensión de la adaptación. La incorporación de esta figura tiene un alto valor simbólico y social, pues incluye al grupo de destinatarios como parte del proceso laboral del servicio, les otorga reconocimiento y expertise y ayuda a los traductores a conocer las limitaciones sensoriales y cognitivas de los receptores del mensaje. $^{16}$

Ya en la segunda década del nuevo siglo, se difunde la traducción al español de la edición revisada de la Guía de la IFLA de 2012, así como el trabajo de García Muñoz (2012) Lectura fácil: métodos de redacción y evaluación y, del mismo autor, Lectura fácil, en el marco de las Guías prácticas de orientaciones para la inclusión educativa (García Muñoz 2014). De forma casi paralela, la traducción al español de las guías de Inclusion Europe se editan en 2013.

Por lo que respecta a los hitos de Plena Inclusión en materia de lectura fácil, destacan la creación de la Cooperativa Altavoz en 2013, una entidad fundada por personas con discapacidad intelectual para hacer textos en lectura fácil, así como la celebración del Congreso Estatal de Accesibilidad Cognitiva, que se celebró en 2017 y reunió una serie de prácticas y experiencias destacables que se estaban dando en nuestro país, tales como un diccionario fácil, experiencias en museos, adaptación de textos sanitarios, sentencias judiciales, acuerdos municipales, etc. ${ }^{17}$ La iniciativa Planeta Fácil, finalmente, contiene un repositorio de noticias, obras literarias y clubes de lectura fácil desde 2017. Por su parte, la web de Plena Inclusión Madrid contiene el Diccionario Fácil, que comenzó su andadura en 2017, y un repositorio de textos no literarios. ${ }^{18}$

Por parte de la Asociación de Lectura Fácil, en 2016 se crea una red de asociaciones para aunar asociaciones de lectura fácil en algunas comunidades autónomas, tales como Euskadi, Castilla y León, Madrid, Castilla la Mancha, Baleares, Aragón o Extremadura. La web de la asociación contiene un repositorio de libros de ficción de más de una decena de editoriales, así como una sección de recursos de textos no literarios ordenados por materia e idiomas.

Por último, la elaboración y publicación de las normas UNE (la UNE 153101 EX y la UNE 153102 EX, que citamos como AENOR 2018 y AENOR 2018a) ha supuesto un hito en España en materia de lectura fácil, así como un elemento diferenciador con el resto de países, ya que es la primera norma mundial elaborada por un organismo de normalización, AENOR. Supone también un trabajo en equipo por parte representantes de la administración pública (el CEAPAT-Imserso) y el Tercer Sector (representantes de Plena Inclusión), aunque en la norma no se encuentra el nombre de los miembros del comité técnico de AENOR (comité de código CTN153/ GT1) que se conformó para redactarlas.

En el ámbito científico, por otro lado, las publicaciones teóricas o empíricas sobre la lectura fácil en España son aún escasas. Se encuentran algunos trabajos desde la psicología experimental y la pedagogía sobre comprensión lectora, tales como Fajardo et al. (2013, 2014), Tavares Sánchez-Monge (2016); Delgado Herrera et al. (2018); grupo EDI (2009); o Vived y Molina (2012). Consideramos relevante los trabajos experimentales de León et al.

(14) Disponible en https://planetafacil.plenainclusion.org/libros/don-quijote-de-la-mancha/

(15) Cita sin paginación procedente de una presentación disponible en formato vídeo en https://www.youtube.com/watch?v=oK7BmxRRnws

(16) Sobre el proceso de validación y sus aspectos sociolaborales, el grupo de expertos de lectura fácil de Plena Inclusión Madrid publicó en 2018 Validación de textos en lectura fácil: aspectos prácticos y

sociolaborales. Disponible en https://plenainclusionmadrid.org/wp-content/uploads/2018/09/Manual-validaci\%C3\%B3n-final.pdf

(17) Informe final del congreso en https://plenainclusion.org/sites/default/files/informe_congreso_ac-dif.pdf

(18) Disponible en https://plenainclusionmadrid.org/publicaciones-y-documentos-en-lectura-facil/ 
(2018) sobre la evidencia de la lectura fácil, por el amplio número de la muestra y las conclusiones aportadas con base en los resultados obtenidos. Sobre la vinculación de la lectura fácil con el español como lengua extranjera, destacan algunos trabajos de Ocampo González (2015) y los mencionados del grupo DILES. Sobre la necesidad de una mayor evidencia científica, véase Rivero Contreras y Saldaña Sage (2020) o Jiménez Hurtado y Medina Reguera (en prensa).

Desde la traductología, destaca el proyecto EASIT: Easy Access for Social Inclusion Training (2018-2021), coordinado por la Universidad Autónoma de Barcelona, que supone un acercamiento teórico a la introducción de los textos simplificados en el ámbito de la traducción audiovisual. La mayoría de los trabajos (Matamala 2019; Arias-Badia y Fernández-Torné 2020) se aplican a los textos audiovisuales y se centran en las competencias y nuevos perfiles profesionales derivados de la accesibilidad cognitiva. Según estos mismos autores, la investigación en lectura fácil se encuentra en una etapa muy incipiente (Bernabé Caro 2018, Bernabé Caro y Orero 2019; Bernabé Caro 2020). En estos trabajos también se aborda la dimensión semiótica de los diferentes servicios de accesibilidad cognitiva, calificándolos como servicios de accesibilidad fáciles de aprender (Bernabé Caro 2020). En la Universidad de Granada, desde el grupo de investigación TRACCE, se han publicado algunos trabajos en el marco del acceso al patrimonio (Carlucci y Seibel 2020). Más reciente es el proyecto coordinado LECPAT, de las universidades de Granada y Pablo de Olavide de Sevilla, sobre lectura fácil y patrimonio, que aplicará el análisis terminológico basado en marcos (Faber et al. 2001, Faber 2011) a la traducción a lectura fácil, describiendo la organización de los posibles conceptos que se incluyen en cada categoría y sus respectivas definiciones, así como las relaciones semánticas y pragmáticas que se activan entre ellos, creando lenguajes simplificados de cada dominio de especialidad (Toribio Camuñas 2020, Jiménez Hurtado y Medina Reguera, en prensa; Seibel y Carlucci 2021).

Por último, algunas publicaciones están abordando la lectura fácil en Derecho, como Ariel Rositto (2015) y García León (2021) sobre textos jurídicos en general, Ariza Colmenarejo (2019) sobre resoluciones judiciales y Pérez Gallardo y Pereira Pérez (2021) sobre sentencias.

\subsection{El desarrollo de Leichte Sprache en Alemania}

Como ya se ha indicado antes, el término oficial por el que se ha traducido Easy-to-Read en Alemania es lengua fácil (Leichte Sprache), si bien usamos aquí lectura fácil como denominación del ámbito y como equivalente de dos sistemas nacionales bastante paralelos. Los comienzos de la lectura fácil en Alemania se encuentran unidos a las iniciativas de Inclusion Europe, fundada a finales de los ochenta. La red Netzwerk Leichte Sprache, que como organismo forma parte del Bundesministerium für Arbeit und Soziales (BMAS), se fundó en 2006 y se considera el organismo principal en la promoción de la lectura fácil en Alemania. El Büro für Leichte Sprache, de la asociación Lebenshilfe Bremen, aparece como participante en el proyecto Pathways, que dio origen a las normas Information for all y cuya traducción al alemán (Informationen für alle. Europäische Regeln, wie man Informationen leicht lesbar und leicht verständlich macht) es del año 2009. Curiosamente, aunque se trata de unas normas transversales y supralingüísticas, la traducción de las normas ya incluye algunas particularidades relativas a la lengua alemana, como la división de palabras compuestas, que es uno de los aspectos más complejos de adaptar, por los desafíos cognitivos que conllevan para muchas personas (Maaß y Rink 2019: 252). En Alemania, para señalar que un texto está redactado en lectura fácil, el logotipo más utilizado es también el de Inclusion Europe, aunque las reglas traducidas desde Inclusion Europe como Information für alle apenas se usan, pues en la práctica han sido sustituidas por las guías de la red Netzwerk Leichte Sprache (ambas son de 2009). El hecho de que las guías de la red estén publicadas en la web del BMAS les concede un aspecto oficial, si bien no son legalmente vinculantes. De forma similar a Plena Inclusión en España, la red Netzwerk Leichte Sprache propone la revisión de los textos por personas con discapacidad intelectual (que actúan como Prüfer und Prüferinnen), aunque no los denomina de esta forma: no se encuentran los términos geistige / intellektuelle / kognitive Behinderung/ Beeinträchtigung; en su lugar domina Menschen mit Lernschwierigkeiten (o, en lectura fácil, Lern-Schwierigkeiten). En la web de la red, además, se puede leer que la lengua fácil alemana sirve para personas que no hablan bien alemán y personas que tienen demencia. ${ }^{19}$

La traducción de las normas de Information for all coinciden en el tiempo con las normas de la red Netzwerk Leichte Sprache, que, a pesar de ser las más extendidas en la actualidad, compiten con las BITV 2.0 (Barrierefreie-

(19) Disponible en Das ist Leichte Sprache - Netzwerk Leichte Sprache (leichte-sprache.org) 
Informationstechnik-Verordnung), que son de 2011 y de cumplimiento obligado. En un anexo de las BITV 2.0 están contenidas 13 normas sobre la adaptación del contenido y del diseño. En palabras de Maaß y Rink (2019: $56)$ :

In Anlage 2 der BITV 2.0 erfolgen konkrete Anweisungen zur Umsetzung in Gebärdensprache (Teil 1) bzw. Leichte Sprache (Teil 2). Bei Letzterem handelt es sich jedoch überwiegend um Vorgaben hinsichtlich des Layouts - nur fünf der 13 Vorgaben beziehen sich auf die tatsächliche sprachliche Umsetzung.

Las guías que conviven son, por tanto, tres: la traducción de las de Inclusion Europe, las de la red Netzwerk Leichte Sprache y las BITV 2.0 (véase Maaß 2020: 74 para una comparación detallada entre ellas). En 2016 se creó la Bundesfachstelle Barrierefreiheit (Oficina Federal de Accesibilidad), que se encarga del asesoramiento en materia de accesibilidad a entidades privadas y públicas. Desde esta web se accede a las reglas BITV y a dos diccionarios en lectura fácil para el alemán: $\operatorname{Hurraki}^{20} \mathrm{y}$ el de la Bundesvereinigung Lebenshilfe. ${ }^{21}$ Desde la web de esta oficina también se derivan los proveedores de servicio Lebenshilfe Bremen, Capito Berlin y Mensch zuerst. En todo momento se describe el servicio como una traducción: «Hier werden Texte übersetzt und geprüft» ${ }^{22}$

Sin embargo, a diferencia de la mayoría de países, la lectura fácil ha despertado el interés de un buen número de investigadores en Alemania, y el número de publicaciones científicas sobre el alemán fácil es elevado con respecto a otras lenguas. En 2014, la investigadora de la Universidad de Hildesheim Christiane Maaß funda el Forschungsstelle Leichte Sprache y publica en 2015 Leichte Sprache. Das Regelbuch, un «libro de reglas basado en la evidencia científica». Solo un año más tarde, esta misma autora, junto con Ursula Bredel (Bredel y Maaß 2016a, 2016b, 2016c, 2017), presenta la trilogía Duden Leichte Sprache, que presenta un libro para la aplicación práctica y un libro de ejercicios para traductores. En los últimos años, Maaß se ha interesado por la aceptabilidad, la estigmatización y el aseguramiento de la calidad en lectura fácil, así como por situar la lectura fácil en el ámbito de la lingüística y de la traductología (Hansen-Schirra y Maaß 2020; Maaß 2020; y Maaß y Rink 201923). Deilen, Hansen-Schirra y Maaß (2019) se ocupan de comprobar en qué medida la norma europea de aseguramiento de calidad de los servicios de traducción ISO 17100 puede adaptarse al proceso traductológico de la lectura fácil.

Sobre la evidencia científica de la lectura fácil se encuentran trabajos desde la pedagogía y desde la traductología. Destacan los trabajos de un grupo de investigación de la Universidad de Leipzig (Bergelt, Goldbach y Seidel 2016; Goldbach y Schuppener 2016; Bock y Lange 2017). Los trabajos de Leipzig abordan la heterogeneidad de los grupos destinatarios desde la sociolingüística, así como los límites entre la lectura fácil y otras modalidades de comunicación accesible. En Bock (2019) se presentan los hallazgos lingüísticos más importantes del proyecto Leichte Sprache im Arbeitsleben (LeiSA, 2014-2018) y se aportan hallazgos sobre hasta qué punto los textos adaptados han resultado comprensibles para los grupos destinatarios. También en Leipzig tuvo lugar un congreso nacional sobre lectura fácil de carácter multidisciplinar, cuyas actas pueden encontrarse en Bock, Fix y Lange (2017).

Desde la Johannes Gutenberg University, de Maguncia, Hansen-Schirra y Gutermuth (2018), Hansen-Shirra y Maaß (2020), Hansen-Schirra et al. (2020), Gutermuth (2020), por su parte, han dedicado sus esfuerzos en varios estudios empíricos y experimentales sobre la mejora de la comprensión lectora en grupos destinatarios mediante cuestionarios, lectores oculares y otros.

Por último, la descripción sobre la lectura fácil como una modalidad de traducción intralingüística puede encontrarse en Maaß 2019, Maaß 2020: 171-179. Pensamos que es contradictorio cuando Maaß afirma que la traducción a lectura fácil puede ser o no intersemiótica (Maaß 2020: 174), dado que en sus trabajos y en la práctica traductora se reafirma que la adaptación lingüística no puede separarse de las modificaciones de diseño, con elementos paratextuales no verbales. No en vano, en Alemania se ha investigado y experimentado en buena medida con el diseño gráfico y las imágenes, gracias, sobre todo, a los trabajos de Alexander (véase, por ej. Alexander 2019). 


\section{Breve descripción de las variedades en ambas lenguas}

\subsection{Características de la lectura fácil en español}

Los textos traducidos a lectura fácil no siempre son fácilmente reconocibles como textos meta de otros textos originales concretos. Esto se debe a que no suelen presentarse conjuntamente, excepto en algunos sitios web, en los que se encuentra la nota «versión en lectura fácil» junto a la versión estándar (en la web de Plena Inclusión es al revés, se presenta el texto en lectura fácil y debajo la versión difícil del mismo texto). Las diferencias entre las normas de la IFLA y las normas UNE se refieren básicamente al proceso de validación, o bien al concepto de una lectura fácil para grupos muy variados de personas con dificultades situacionales o transitorias (español como lengua extranjera, niños de primaria), frente a otro concepto de lectura fácil más restrictivo, dirigido a personas con discapacidad intelectual y del desarrollo y en cuya validación estas deben estar necesariamente presentes. Más allá de estas diferencias, los textos meta presentan una pretendida simplificación sintáctica y léxica basadas en una serie de indicaciones generales. Con respecto al formato y la maquetación del texto, los textos en lectura fácil se reconocen fácilmente; la mayoría de los aspectos formales proceden de las guías de Inclusion Europe (2010: 12): tipo de fuente sin serifa y mayor de lo habitual, alineación izquierda, reestructuración de los párrafos con oraciones cortas e interlineado entre ellos, definiciones del vocabulario elegido a la derecha (glosas) y algunas imágenes o pictogramas.

Aunque algunas guías fundacionales ya mencionadas arriba incluyen niveles de lectura fácil, no resulta una práctica habitual en nuestro país. Las guías de la IFLA establecen tres niveles: el nivel I es el más fácil, el texto es corto y sintáctica y lingüísticamente sencillo, con abundantes ilustraciones; el nivel II representa expresiones y vocabulario del día a día, ilustraciones y acciones fáciles; por último, el nivel III es el de mayor complejidad, textos más extensos, con algunas palabras poco usuales y expresiones en sentido figurado, con saltos espaciotemporales y muy pocas ilustraciones. A pesar de que se observan diferencias notables entre algunos textos adaptados a lectura fácil y otros, no se encuentra en los propios textos ninguna alusión a qué nivel corresponden.

Relacionado con esto, la editorial SGEL publicó una serie de textos en lectura fácil ${ }^{24}$ y estableció unos niveles de dificultad siguiendo el Plan Curricular del Instituto Cervantes (PCIC) y el Marco Común Europeo de referencia para las Lenguas (MCER). El nivel inicial correspondería al nivel A1-A2 del MCER, adecuado para un usuario básico de la lengua: textos breves (500-1200 palabras) con vocabulario muy frecuente y de uso cotidiano, la longitud de las oraciones de 15 palabras máximo, y con la estructura sintáctica SVO. El nivel intermedio, por su parte, se situaría en el nivel B1, hasta las 2000 palabras, con léxico de frecuencia alta y longitud oracional de hasta 20 palabras. Y, por último, situándonos en el nivel avanzado (B2-C1 del MCER), el léxico se sitúa en máximo 3000 palabras, de frecuencia moderada y más de 20 palabras de longitud oracional (García Muñoz: 2012: 23). Sin embargo, esta perspectiva no está exenta de problemas, dado que los niveles de MCER están preparados para la adquisición activa de una lengua y no para la comprensión y porque la disponibilidad léxica del español según niveles del MCER tampoco está aún desarrollada (Bartol Hernández 2010). Asimismo, la adaptación por niveles podría, al acotar el léxico en compartimentos cerrados, segregar a los destinatarios: así, suele afirmarse que las personas con TEA (trastorno del espectro del autismo) no verbales necesitan adaptaciones pictográficas, con lo que, si le ofreciéramos de forma generalizadas adaptaciones de nivel 1, siempre tendrían a su disposición léxico escaso y muy familiar, algo que podría considerarse estigmatizador y poco inclusivo, sobre todo teniendo en cuenta que la lectura es una herramienta para avanzar en el acceso al conocimiento. No en vano, una de las conclusiones en el estudio experimental de León et al. demuestra que, a mayor nivel educativo, mayor es la comprensión lectora: «Una variable relevante de las personas con $\mathrm{DID}^{25}$ fue su nivel educativo, pues cuanto más alto era su nivel, mejor rendimiento y mejor nivel de competencia lectora mostraron» (León et al. 2018: 5).

Tanto si se siguen las guías de Inclusion Europe como la norma UNE 2018, el proceso por el cuál se adapta un TO a un TM es el mismo, con dos fases diferenciadas (véase ilustración 1): una fase de adaptación que genera un primer borrador, y una fase de validación que a su vez puede ser doble o repetirse ad infinitum hasta que un grupo de validadores dé el visto bueno al texto final.

En la primera fase se realiza la lectura, estudio, observación y análisis de los materiales originales. Se propone

(24) Las lecturas a las que nos referimos se pueden encontrar en: https://ele.sgel.es/ja/producto-descarga?producto_id=794\&tipo=nivel\&tipoDescarga=Alumnos (25) Discapacidad intelectual o del desarrollo. La nota es nuestra. 
un texto traducido para su revisión. En la segunda fase, la fase de validación, se conforma un grupo de personas con discapacidad, denominadas validadores y coordinadas por el dinamizador. A esta validación le sigue un informe y un nuevo borrador con la incorporación de las aportaciones del grupo y aprobado por el autor del material.

Con respecto al proceso de creación o adaptación de textos a lectura fácil, las normas detallan el proceso a seguir, para lo que son necesarios un autor o adaptador (AENOR 2018: 6), que crea o adapta el texto en su versión de lectura fácil. Para que estos documentos sean considerados lectura fácil, la versión final del documento debe ser comprobada en un proceso de validación específico, también descrito en la norma. El proceso debe estar coordinado por un dinamizador, que, teniendo en cuenta una serie de factores, dirige la sesión con los validadores. La norma UNE (AENOR 2018: 10) establece que el grupo de validadores debe comprender entre un mínimo de tres y un máximo de ocho personas con problemas de comprensión lectora. Los dinamizadores, lideran el grupo de validadores, hacen preguntas y elaboran un informe sobre los cambios necesarios para el adaptador o maquetador.

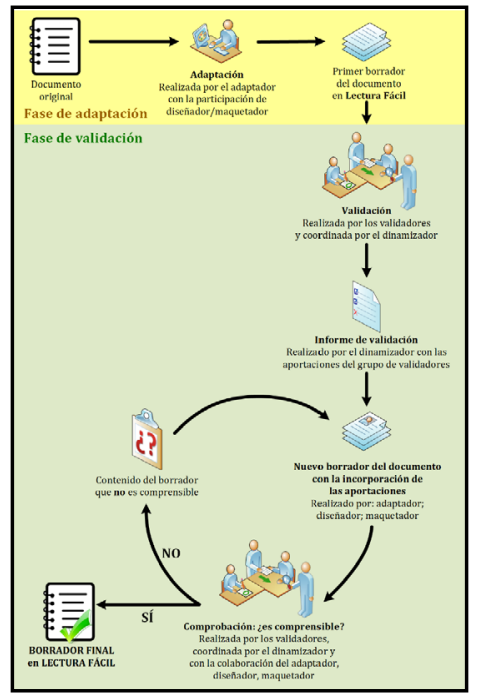

Ilustración 1: Flujograma de la metodología de la lectura fácil en la norma UNE 153101:2018 EX (AENOR 2018: 12)

La norma UNE está formada por siete capítulos, y se centra, por una parte, en el «proceso de trabajo» para la adaptación o para la creación de un «documento» en lectura fácil. Los capítulos sexto y séptimo se dedican a las pautas y recomendaciones relacionadas para la redacción y el diseño, en total, nueve elementos: Ortotipografía, vocabulario, oraciones, organización del texto, diseño, presentación, imágenes, complementos paratextuales verbales y complementos paratextuales icónicos.

La mayoría de las pautas son tan generales que podrían aplicarse a todas las lenguas. Sin embargo, algunas pocas pautas se refieren a las particularidades del español: no usar adverbios terminados en -mente, no usar la pasiva refleja, perífrasis verbales o formas compuestas de los verbos. A continuación, mostramos dos ejemplos tal y como aparecen en la norma:

Se debería evitar en lo posible el uso de oraciones con gerundio.

EJEMPLO:

(INCORRECTO) Jorge estaba cantando en su casa cuando sonó el timbre.

(CORRECTO) Jorge cantaba en su casa y sonó el timbre. (AENOR 2018: 23)

Se debería evitar la pasiva refleja.

EJEMPLO:

(INCORRECTO) Se venden casas.

(CORRECTO) Vendemos casas. (AENOR 2018: 22) 
La norma también incluye ejemplos de cómo deben ser las imágenes o de cómo organizar los complementos paratextuales, por ej., ante la pauta «las imágenes deben ser claras, sin encuadres complejos ni abstracciones», para macetero, la norma propone la segunda de las siguientes opciones:

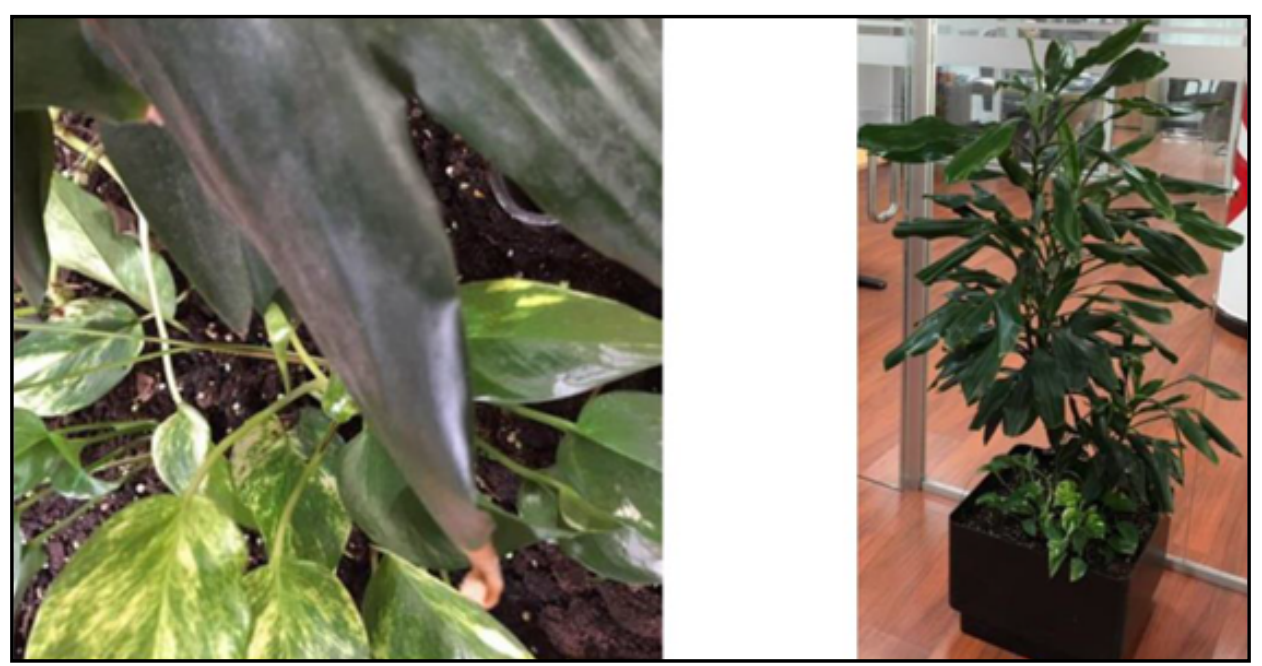

Ilustración 2: Captura de la norma UNE (2018: 30)

A continuación, abordaremos brevemente algunas características para la práctica de la lectura fácil en alemán.

\subsection{Características de la lectura fácil en alemán}

Como ya se ha desarrollado más arriba, para redactar y adaptar textos en lectura fácil en alemán existen varios manuales y conjuntos de normas disponibles, tanto desde las asociaciones como desde el ámbito académico. En cierto modo, las diversas normas compiten entre sí, y aquellas que se consideran normas científicas vienen avaladas por la editorial Duden y no encuentran forma homónima en español. La función principal de los textos es que las personas con barreras lingüísticas tengan acceso a la información, fomentando su participación en la comunicación y en la sociedad. Dado que el foco de la Leichte Sprache (lengua fácil) no está puesto en la lectura, no encontramos en alemán la expresión personas con problemas de comprensión lectora, sino personas con dificultades de aprendizaje, personas sordas, personas analfabetas y personas que no conocen la lengua. En general, el término discapacidad intelectual se encuentra con mucha menos frecuencia que en español, aunque se trata de una cuestión terminológica basada en una motivación ideológica, más que un asunto de fondo sobre los grupos destinatarios a lo que esta va dirigida. La diferencia de las barreras intrínsecas individuales de los grupos destinatarios primarios y otros grupos y colectivos (que podríamos llamar secundarios, porque también se beneficiarían de la lectura fácil), ha sido ampliamente expuesto por Maaß:

Thus, there appears to be an inconsistency regarding the policy toward target groups as well as the role of text producers that leads to a text practice that is problematic with respect to the acceptability of the texts produced under these circumstances. This inconsistency is linked to the symbolic function of Easy Language and not easy to solve (Maßß 2020: 72).

Las reglas de la red Netzwerk Leichte Sprache son las más usadas entre el movimiento asociativo. Están escritas en lectura fácil y se dividen en seis apartados: Wörter; Zahlen und Zeichen, Sätze, Texte, Gestaltung und Bilder y Prüfen. Son mucho más generales que las reglas del Duden Leichte Sprache, donde se desgrana la reducción sistemática de la complejidad, que se consigue tanto con estrategias de reducción (Maaß 2015: 12) como con estrategias de adición (Bredel y Maaß 2016a: 489; Bredel y Maaß 2016b: 154).

En el apartado de léxico, se propone el uso de palabras frecuentes y generales, cortas o, cuando esto no sea posible, con guion de separación entre los miembros de un compuesto (por ejemplo, Bundes-GleichstellungsGesetz). Se propone ejemplificar en detrimento del uso de hiperónimos, como en el ejemplo Bus und Bahn 
(autobús y metro) en lugar de Öffentlicher Nahverkehr (medios de transporte públicos) ${ }^{26}$. Bredel y Maaß (2016) han propuesto en la serie de tres obras Duden Leichte Sprache el uso del punto medio o interpunto (Zusammen.arbeit) para evitar los problemas de aceptación que puede generar la división en guiones de los compuestos (véase Maaß 2015: 88). El grado de aceptación o rechazo de los textos es un tema que ha ocupado un buen número de los últimos trabajos de Maaß, y en concreto Easy Language - Plain Language - Easy Language Plus. Balancing Comprehensibility and Acceptability (Maaß 2020). Con frecuencia, la autora se refiere a una situación ocurrida en las elecciones de Schleswig-Holstein en 2017, en las que, siguiendo una nueva ley electoral, todos los votantes recibieron folletos y notificaciones electorales en lectura fácil, siguiendo la premisa del diseño universal o diseño para todas las personas; todos entienden la lectura fácil, porque representa un común denominador, esto es, un término intermedio útil para la inmensa mayoría. Sin embargo, los textos no fueron aceptados por la población: los ciudadanos redactaron cartas de reclamación a la prensa y los medios de comunicación audiovisuales se hicieron eco del malestar general. Los motivos oscilaban entre un alemán incorrecto, ofensivo, que hacía sentir estúpidos a los ciudadanos (Maaß 2020: 66). Como consecuencia, se impulsó una nueva modificación de la ley electoral, a partir de la cual los textos en lectura fácil solo están disponibles online o bajo demanda (Maaß y Rink 2019: 264).

Las restricciones sintácticas se centran en la morfología del verbo, con reglas que piden evitar la voz pasiva o el Konjuntiv (En lugar de Morgen könnte es regnen, debe decirse Morgen regnet es vielleicht). No debe usarse el genitivo, así como deben buscarse alternativas para la negación y para la subordinación. ${ }^{27}$

Desde el punto de vista del diseño y la maquetación, no existen diferencias con las directrices que vienen de Inclusion Europe: los textos están alineados a la izquierda, la fuente preferible será sin serifa de tamaño 14, están casi siempre acompañados de imágenes y con interlineados amplios:

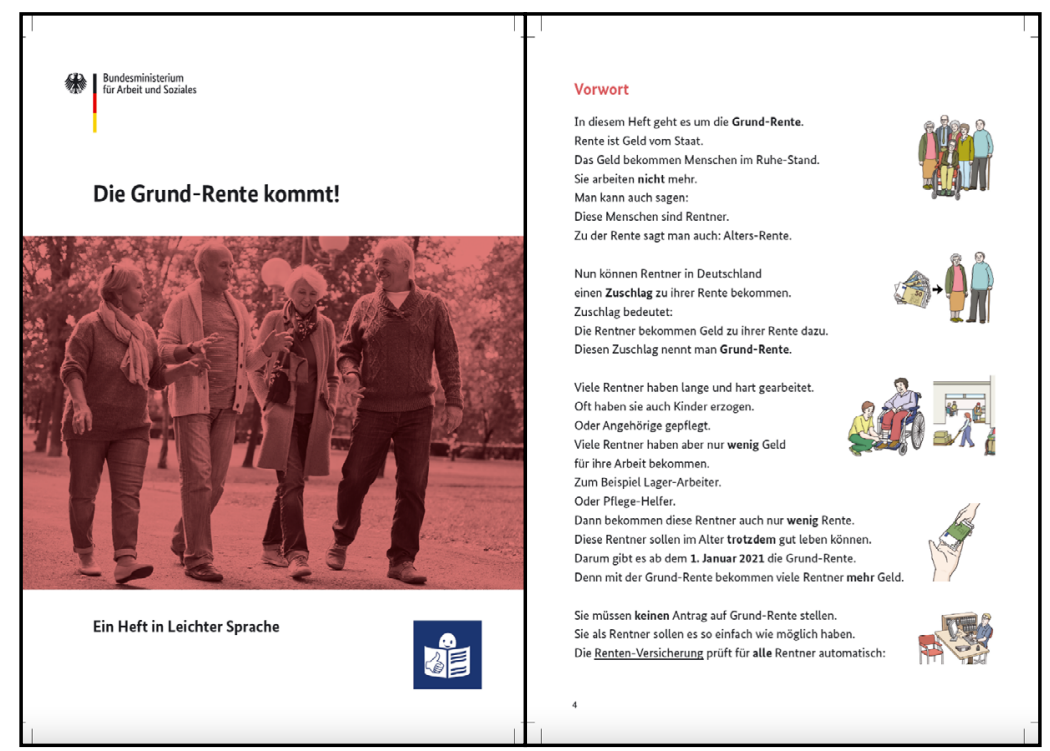

Ilustración 3: Ejemplo de texto en lectura fácil en el apartado de lectura fácil del BMAS²8

Por último, la mayoría de los textos que pueden encontrarse en lectura fácil en Alemania son textos informativos del ámbito de la administración y la política, la salud y el derecho. A diferencia de España, y en relación con el volumen total, no se encuentran apenas textos literarios. En cambio, en Alemania existen bastantes trabajos sobre el efecto de las imágenes y los elementos paratextuales sobre los grupos objetivos de la lectura fácil (Alexander 2019).

\section{Regulación jurídica y normas vinculantes}

\subsection{Regulación jurídica y normativa de la lectura fácil en España}

En la actualidad no existe aún ninguna norma legal nacional que regule u obligue a las administraciones

(26) Ejemplo tomado de las normas de Netzwerk Leichte Stelle (2013: 4), disponible en https://www.leichte-sprache.org/wp-content/uploads/2017/11/Regeln_Leichte_Sprache.pdf (27) Véase https://www.leichte-sprache.org/wp-content/uploads/2017/11/Regeln_Leichte_Sprache.pdf

(28) Texto completo en https://www.bmas.de/DE/Leichte-Sprache/Publikationen-leichte-Sprache/publikationen-leichte-sprache.html 
a ofrecer la lectura fácil (tampoco el lenguaje claro). El Real Decreto Ley 1/2013, por el que se aprueba la Ley General de derechos de las personas con discapacidad y de su inclusión social no la incluye explícitamente. En las leyes autonómicas, se encuentra la lectura fácil mencionada en la Llei 13/2014, de 30 d'octubre, d'accessibilitat ${ }^{29}$ que hace referencia a la accesibilidad cognitiva y a la lectura fácil. La Asociación de Lectura Fácil participa en las enmiendas del articulado de la ley y la adapta.

Como ya se ha explicado en un apartado anterior, España cuenta con las Normas de AENOR (2018) UNE 153101 EX (Lectura Fácil: pautas y recomendaciones para la elaboración de documentos) y AENOR (2018a) UNE 153102 EX (Guía en Lectura Fácil para validadores de documentos). Estas normas recogen un marco metodológico existente para la adaptación o creación de textos en lectura fácil, pero no son de obligado cumplimiento. Las normas han sido elaboradas por el comité técnico CTN 153 Productos de apoyo para personas con discapacidad.

Desde CERMI y la Federación Plena Inclusión se ha solicitado la regulación de la accesibilidad cognitiva en el marco de una reforma de la Ley1/2013, pero sin resultados hasta la fecha actual.

\subsection{Regulación jurídica y normativa de la lectura fácil en Alemania}

En Alemania, las leyes más importantes que regulan la accesibilidad son la Behindertengleichstellungsgesetzt, BGG, de 2002, la Barrierefreie-Informationstechnik-Verordnung, BITV 2.0, de 2011. En la versión de la BGG de 2016, se introduce el párrafo 11 sobre comprensibilidad y lenguaje fácil ( $\$ 11$ "Verständlichkeit und Leichte Sprache"), que entró en vigor en enero de 2018 y obliga a las administraciones públicas a tener versiones en lectura fácil de documentos públicos, siempre que a) una versión de estos en lenguaje claro no sea suficiente y b) siempre que se exijan explícitamente. Los tipos de textos a los que se refiere la ley «en especial» (insbesondere) son notificaciones (Bescheide), disposiciones generales (Allgemeinverfügungen), contratos públicos (öffentlichrechtliche Verträge) y formularios (Vordrucke):

$\$ 11$ Verständlichkeit und Leichte Sprache

(1) Träger öffentlicher Gewalt sollen mit Menschen mit geistigen Behinderungen und Menschen mit seelischen Behinderungen in einfacher und verständlicher Sprache kommunizieren. Auf Verlangen sollen sie ihnen insbesondere Bescheide, Allgemeinverfügungen, öffentlich-rechtliche Verträge und Vordrucke in einfacher und verständlicher Weise erläutern

(2) Ist die Erläuterung nach Absatz 1 nicht ausreichend, sollen Träger öffentlicher Gewalt auf Verlangen Menschen mit geistigen Behinderungen und Menschen mit seelischen Behinderungen Bescheide, Allgemeinverfügungen, öffentlich-rechtliche Verträge und Vordrucke in Leichter Sprache erläutern. ${ }^{30}$

De la ley se desprenden una escala entre el lenguaje claro (Einfache Sprache) y la lectura fácil (Leichte Sprache), como un nivel siguiente de comprensibilidad, así como el hecho de que la obligación jurídica solamente se ciñe a determinados textos administrativos.

El tercer punto del párrafo 11 indica quién debe cubrir el servicio: los costes correrán a cargo de las autoridades competentes y la cantidad o extensión del servicio se determinará en función de las necesidades individuales de los derechohabientes: «(3) Kosten für Erläuterungen im notwendigen Umfang nach Absatz 1 oder 2 sind von dem zuständigen Träger öffentlicher Gewalt zu tragen. Der notwendige Umfang bestimmt sich nach dem individuellen Bedarf der Berechtigten». El cuarto punto, por fin, anima a que los textos en lectura fácil aumenten paulatinamente en Alemania: las autoridades públicas proporcionarán cada vez más información en lenguaje fácil y el gobierno se esforzará por aumentar su uso, así como por desarrollar y ampliar sus competencias para la redacción de esta modalidad:

(4) Träger öffentlicher Gewalt sollen Informationen vermehrt in Leichter Sprache bereitstellen. Die Bundesregierung wirkt darauf hin, dass die Träger öffentlicher Gewalt die Leichte Sprache stärker einsetzen und ihre Kompetenzen für das Verfassen von Texten in Leichter Sprache auf- und ausgebaut werden. ${ }^{31}$

En resumen, en Alemania conviven varias normas y planteamientos. Por un lado, las guías de la red Netzwerk Leichte Sprache; por otro, las del Duden Leichte Sprache y por otro, las BITV 2.1. Además, actualmente se

(29) Disponible en https://portaljuridic.gencat.cat/ca/document-del-pjur/?documentId=673958

(30) Gesetz zur Gleichstellung von Menschen mit Behinderungen (Behindertengleichstellungsgesetz - BGG). Disponible en https://www.gesetze-im-internet.de/bgg/BJNR146800002.html

(31) Igual que nota anterior. 
trabaja en la elaboración de una norma alemana, con más de 70 expertos divididos en cinco grupos de trabajo, la DIN SPEC 33429 Empfehlungen für Deutsche Leichte Sprache ${ }^{32}$. Se trata de una prenorma (equivalente a norma experimental, en España) con recomendaciones específicas, si bien no será de obligado cumplimiento. A diferencia de España, son gratuitas, por lo que la difusión es mucho mayor. Se trata de un proceso colaborativo en el que trabajan todos los agentes. Incluye recomendaciones para la lectura fácil en alemán, estableciendo un conjunto unificado de normas que describen los aspectos lingüísticos gramaticales, léxicos, ortográficos, de puntuación, etc. Incluyen también concreciones sobre la maquetación y el diseño, el tamaño de la fuente, el espaciado, los colores y contrastes. Finalmente, la norma debe incluir recomendaciones sobre la formación de validadores, dinamizadores, adaptadores y autores.

\section{Conclusiones: Similitudes y diferencias}

La discapacidad es una realidad social y jurídica, que definimos, según la Convención Internacional sobre los Derechos Humanos de las Personas con Discapacidad de Naciones Unidas, como una situación que resulta de la interacción entre las personas con limitaciones (físicas, sensoriales, orgánicas o cognitivas, en mayor o menor grado permanentes) y cualquier tipo de barreras que limiten o impidan su participación plena y efectiva en la sociedad, en igualdad de condiciones con las demás personas.

Gracias a entidades del tercer sector, del movimiento asociativo de la discapacidad y de otras organizaciones públicas, se ha convertido en un elemento transversal en múltiples ámbitos, como el periodístico, el legislativo, el cultural, el literario, el sanitario y el educativo. Cubre una necesidad social que permite garantizar el derecho de acceso a la información escrita en igualdad de condiciones. El acceso a la información es imprescindible para ejercer la plena ciudadanía.

La lectura fácil surge en ambos países de forma similar y de la mano de la Unión Europea, que ha apoyado y financiado al movimiento asociativo internacional de la discapacidad. En el mismo número de años, el desarrollo ha discurrido de forma más o menos paralela, aunque con algunas diferencias, que resumimos a continuación.

En España, las prácticas de traducción a lectura fácil emanan de dos grandes entidades del sector asociativo: la Asociación Lectura Fácil y las asociaciones asociadas a su red, por un lado, y las asociaciones miembros de la Federación de asociaciones Plena Inclusión, por otro. La primera de ellas no ha participado en la elaboración de las normas UNE de AENOR y no las sigue, a diferencia de Plena Inclusión. La principal diferencia entre ambas entidades reside en el proceso de validación, la figura de los validadores y del dinamizador. Para las asociaciones de Plena Inclusión, que sigue tanto la norma UNE como las pautas de Inclusion Europe, es crucial la validación de una o varias personas con problemas de comprensión lectora para la publicación del documento, es decir, para poder considerar el texto como válido, terminado o cualitativamente aceptable. Los nombres de los traductores (adaptadores, en su terminología) y los validadores deben estar visibles en los créditos. El segundo modelo, en cambio, deja el proceso de revisión en manos de los adaptadores: la Asociación de Lectura Fácil no rechaza la validación, pero para ellos este concepto es «flexible» y se acomete la validación dependiendo de cada proyecto y sus destinatarios. Esta asociación adapta los textos sobre la base de la guía de la IFLA. Las normas UNE de AENOR, por ser las primeras del mundo, son un hito importante y sitúan la lectura fácil en España en un lugar privilegiado. En Alemania, se estima que la norma DIN SPEC 33429, estará lista a mediados de 2022, y, mientras llega, la lengua fácil alemana se extiende rápidamente gracias al imperativo legal que llegó con las BITV 2.0. en 2019.

Desde el punto de vista terminológico, la diferencia entre el alemán Leichte Sprache (que literalmente equivale a lengua o lenguaje fácil) y el español lectura fácil es importante, porque, mientras que la primera coloca el adjetivo fácil sobre la variedad de la lengua, la segunda se enfoca en el proceso lector, en las cualidades que los convierten no solo en fáciles, sino en fáciles de leer, y otorgándole a los procesos de decodificación, inferencia o reformulación una importancia mayor. No son, por tanto, términos totalmente paralelos, pues se encuentran en niveles diferentes. La dimensión lectora está presente también en otras lenguas, como ha recopilado Perego (2020). Por el contrario, sí se habla en español de lenguaje claro (Einfache Sprache: lengua sencilla en alemán, 
plain language en inglés) y no de lectura clara. Otra ventaja que tiene el uso de Leichte Sprache en alemán es que puede usarse de forma transversal para textos audiovisuales, en subtítulos, en podcasts, o incluso para personas que reciben textos sin palabras porque no saben leer (Maaß 2020: 55). El hecho de que la traducción de Easyto-Read en español sea lectura fácil ha influido también en que algunos investigadores especializados en los procesos lectores, sobre todo desde la psicología, hayan escrito la mayoría de los escasos trabajos científicos sobre este tema en España.

Otras diferencias terminológicas afectan a los grupos destinatarios yhemos encontrado algunas incongruencias en las traducciones. Por ejemplo, en la traducción al alemán de las guías de Inclusion Europe Information for all, se traducen del inglés intellectual disabilities como Menschen mit Lernschwierigkeiten. ${ }^{33}$ Aunque no entraremos en las implicaciones de las opciones elegidas, éstas resultan sumamente interesante, porque no todas las personas con dificultades de aprendizaje tienen una discapacidad intelectual asociada (véase ilustración 4):

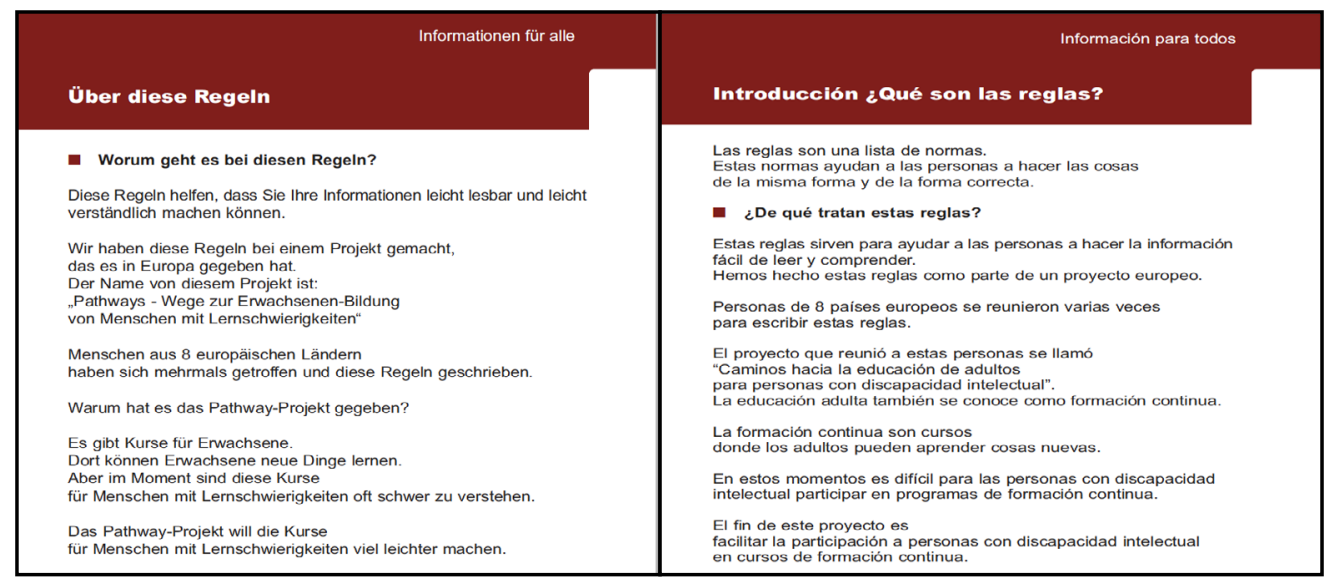

Ilustración 4: Fragmento de las reglas de Inclusion Europe en su traducción al alemán y al español. Elaboración propia

Otra diferencia que nos interesa especialmente es la definición de la lectura fácil como un proceso de traducción o de adaptación. En Alemania, la lectura fácil está plenamente establecida como una modalidad de traducción y apenas se usan otros verbos, como adaptar o redactar, a diferencia de lo que ocurre en España. La inclusión de la lectura fácil en las leyes, el cumplimiento de estas y la creación de una oficina pública le han concedido un reconocimiento oficial que aún no existe en España. Sin embargo, es llamativo que el número de libros de ficción y obras literarias clásicas adaptadas es bastante superior en España.

Un aspecto contrastivo adicional es que en Alemania se está centrando el debate (socio)lingüístico en el grado de aceptación de estos textos por parte de los receptores y las personas que los representan, algo de lo que no hemos encontrado constancia escrita para el español. Se debate en Alemania la relación entre las normas y el estigma que puede traer consigo la lectura fácil y el hecho de que sirva para «señalar» a las personas de manera pública como diferentes por sus problemas de comprensión. Por otro lado, se ha argumentado que algunas personas podrían saltar de la lectura fácil a textos estándar si se les ofrecieran estos últimos, o bien que hay usuarios que solo necesitarían la lectura fácil dependiendo de la especialización de los textos. También se ha cuestionado la estética de lo fácil, es decir, textos desproveídos de metáforas, juegos de palabras, colores, etc. Y, por último, se han cuestionado algunas normas concretas, sobre todo la separación de palabras compuestas con guion y otras normas que convierten la lengua alemana en una variedad que no coincide con la norma ortográfica estándar, algo que no ocurre en el español. En qué medida la variedad del español es poco marcada respecto a la variedad alemana es algo que debería ser estudiado con mayor profundidad en próximos trabajos.

En general, las evidencias empíricas de la lectura fácil no son muy sólidas. La investigación desarrollada en Alemania es superior, tanto por el número de trabajos descriptivos como experimentales. Llama la atención el poco interés suscitado entre investigadores lingüistas, psicólogos o traductores en España, si bien se observa un aumento paulatino de los trabajos en los últimos cinco años. Esta investigación incipiente contrasta con una práctica traductora frecuente y prolija en el seno de asociaciones y federaciones españolas: Plena Inclusión

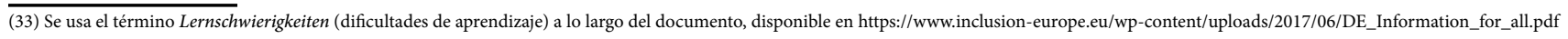


y la Asociación de Lectura Fácil, junto con otros organismos estatales como CERMI y CEAPAT - IMSERSO, son agentes muy dinámicos en la producción de textos en lectura fácil. En Alemania, mientras tanto, se vienen consolidando varias líneas de investigación en las universidades de Maguncia ${ }^{34}$, Hildesheim ${ }^{35}$ y Leipzig ${ }^{36}$.

Sería deseable, por tanto, el aumento de proyectos de investigación, en general, y de trabajos empíricos, en particular, con el objeto de medir la mejora de la comprensión lectora de estos textos meta respecto de sus textos estándar originales. De igual modo consideramos que serían de utilidad estudios de corte sociológicos en los que se pudiera corroborar científicamente cómo y hasta qué punto la lectura fácil es un instrumento que aumenta la participación activa y la autonomía de sus destinatarios en la educación, el trabajo, la vida privada o el ocio.

(34) https://leichtesprache.uni-mainz.de/

(35) https://www.uni-hildesheim.de/leichtesprache/

(36) https://research.uni-leipzig.de/leisa/

Bibliografía:

AENOR (2018). UNE 153101:2018 EX. Lectura Fácil. Pautas y recomendaciones para la elaboración de documentos. UNE.

AENOR (2018a). UNE 153102:2018 EX Guía en Lectura Fácil para validadores de documentos. UNE.

Alexander, K. (ed.) (2019). Mit Typografie und Bild barrierefrei kommunizieren: Forschungsstand und Studien. Frank \& Timme.

Anula Rebollo, A., Fernández-Lagunilla, M. Belinchón Carmona, M., Revilla Guijarro A. y Heras Sedano, L. (2006). Introducción $a$ Don Quijote de la Mancha de fácil lectura. Fundación General de la Universidad Autónoma de Madrid. https://portal uc $3 \mathrm{~m}$. es/portal/page/portal/orientacion personal_participacion/PIED1/lectura_facil/ documentos/94ffd $9 \mathrm{~d} 5$ introduccion quijote fl.pdf

Anula Rebollo, A. (2021). Intervención Alberto Anula en InnoUAM IndustriasCulturales. Presentación disponible en https://www youtube.com $/$ watch? $\mathrm{v}=\mathrm{oK} 7 \mathrm{BmxRRnws}$

Arias-Badia, B. y Fernández-Torné, A. (2020) El experto en lenguaje fácil de comprender: un nuevo perfil educativo y profesional en el ámbito de la lengua española. MonTI. Monografias de Traducción e Interpretación. 12 (mayo 2020), 295-312. https://doi. org/10.6035/MonTI.2020.12.10

Ariel Rositto, S. (2015). ¿El lenguaje es inclusivo en los textos jurídicos? La equiparación de oportunidades para todas las personas a través de la lectura fácil. En A. A. Ocampo González (coord.), Lectura para todos. E aporte de la fácil lectura como vía para la equiparación de oportunidades (pp. 265 276). Asociación Española de Comprensión Lectora.

Ariza Colmenarejo, M. J. (2019). Lectura fácil y resoluciones judiciales. En P. Llopis Nadal, E. de Luis García, F. Jiménez Conde y R. Bellido Penadés (dir.), ¿Garantías ,versus “ eficiencia? (pp. 537-548). Tirant lo Blanch.

Bartol Hernández, J. A. (2010). Disponibilidad léxica y selección del vocabulario. En $\mathrm{R}$. M. Castañer Martín y V. Lagüens Gracia (coord.), De moneda nunca usada: Estudios dedicados a José $M^{a}$ Enguita Utrilla (pp. 85 107). Instituto Fernando el Católico, CSIC.
Behindertengleichstellungsgesetz des Bundes (BGG). (27 de abril de 2002). Gesetz zur Gleichstellung von Menschen mit Behinderungen. http://www.gesetze-iminternet.de/bgg/index.html

Belinchón, M., Casas, S., Díez, C. y Tamarit, J. (2014). Accesibilidad cognitiva en los centros educativos. Ministerio de Educación, Cultura y Deporte. Secretaría General Técnica.

Bergelt, D., Goldbach, A. y Seidel, A. (2016) Leichte Sprache im Arbeitsleben. Analyse der derzeitigen Nutzung von Texten in Leichter Sprache im beruflichen Kontex von Menschen mit Lernschwierigkeiten. Teilhabe 55(3), 106-113.

Bernabé Caro, R. (2018). Propuesta metodológica para el desarrollo de la lectura fácil según el diseño centrado en el usuario. Revista española de discapacidad, 5(2), 19-51. http://dx.doi.org/10.5569/2340 5104.05.02.02

Bernabé Caro, R. (2020). Easy audiovisual content for all: Easy-to-Read as an enabler of easy, multimode access services. [Tesis de doctorado no publicada]. Universitat Autònoma de Barcelona.

Bernabé Caro, R. y Orero, P. (2019). Easy to Read as Multimode Accessibility Service. Hermeneus. Revista de Traducción e Interpretación, 21, 53-74. https://doi. org/10.24197/her.21.2019.53-74

Bock, B. (2019). Leichte Sprache - Kein Regelwerk. Sprachwissenschaftliche Ergebnisse und Praxisempfehlungen aus dem LeiSA-Projekt. Frank \& Timme.

Bock, B. y Lange, D. (2017). Empirische Untersuchungen zu Satz- und Textverstehen bei Menschen mit geistiger Behinderung und funktionalen Analphabeten. En B. Bock, U. Fix, y D. Lange (eds.), „Leichte Sprache“ im Spiegel theoretischer und angewandter Forschung (pp. 253-273). Frank \& Timme.

Bock, B., Fix, U. y Lange, D. (eds.) (2017) „Leichte Sprache“ im Spiegel theoretischer und angewandter Forschung. Frank \& Timme.

Bredel, U. y Maaß, C. (eds.) (2016a). Leichte Sprache. Theoretische Grundlagen. Orientierung für die Praxis. Duden.

Bredel, U. y Maaß, C. (eds.) (2016b). Ratgeber Leichte Sprache. Die wichtigsten Regeln und
Empfehlungen für die Praxis. Duden.

Bredel, U. y Maaß, C. (eds.) (2016c). Leichte Sprache. Arbeitsbuch. Duden.

Bredel, U. y Maaß, C. (2017). Wortverstehen durch Wortgliederung - Bindestrich und Mediopunkt in Leichter Sprache. En B. Bock, U. Fix, y D. Lange (eds.), „Leichte Sprache" im Spiegel theoretischer und angewandter Forschung (pp. 211-228). Frank \& Timme

Carlucci, L. y Seibel, C. (2020). El discurso especializado en el museo inclusivo: lectura fácil versus audiodescripción. En M. Richart-Marset y F. Calamita (eds.), Traducción y Accesibilidad en los medios de comunicación: de la teoría a la práctica / Translation and Media Accessibility: from Theory to Practice (pp. 262-294). MonTI 12.

Deilen, S., Hansen-Schirra, S. y Maaß, C (2019). Anwendbarkeit der ISO 17100 au intralinguales Übersetzen in Leichte und Einfache Sprache. Magazin 27,43-55. https:// dx.doi.org/10.12795/mAGAzin.2019.i27.03

Delgado Herrera, P; Ávila Clemente, V Fajardo Bravo, I; Salmerón González, L. (2018). Un Programa de formación en Lectura Crítica en Internet para jóvenes con Discapacidad Intelectual. Revista española de discapacidad, 6(2), 229 - 245. https://doi. org/10.5569/2340-5104.06.02.13

EDI (Grupo Educación y Diversidad). (2009). Lectura fácil, estructura textual y comprensión lectora en niños con discapacidad y niños inmigrantes [Archivo PDF]. http://www.grupo-edi.com/lectura facil.pdf

Faber, P. (2011). The dynamics of specialized knowledge representation: Simulational reconstruction or the perception-action interface. Terminology International Journal of Theoretical and Applied Issues in Specialized Communication, 17(1), 9-29. http://dx.doi.org/10.1075/term.17.1.02fab

Faber, P., López Rodríguez, C. I. y Tercedor, M. (2001). Utilización de técnicas de corpus en la representación del conocimiento médico. Terminology. International Journal of Theoretical and Applied Issues in Specialized Communication, 7(2), 167-198. https://doi.org/10.1075/term.7.2.04fab

Fajardo, I., Tavares, G., Ávila, V. y Ferrer, A. (2013). Towards text simplification for poor 
readers with intellectual disability: When do connectives enhance text cohesion? Research in Developmental Disabilities, 34(4), 1267-1279. https://doi.org/10.1016/j. ridd.2013.01.006

Fajardo, I., Avila, V., Ferrer, A., Tavares, G, Gómez, M. y Hernández, A. (2014). Easy-to-read texts for students with intellectual disability: Linguistic Factors affecting comprehension. Journal of Applied Research in Intellectual Disabilities, 27(3), 212-225. https://doi.org/10.1111/jar.12065

García León, S. (2021). La lectura fácil en Derecho. Un paso más hacia la plena inclusión. En M. D. Madrid Cruz (dir.), E jurista y el reto de un Derecho comprensible para todos (pp. 113-132). Reus.

García Muñoz, Ó. (2012). Lectura fácil: Métodos de redacción y evaluación. Real Patronato de Discapacidad.

García Muñoz, Ó. (2014). Guías prácticas de orientaciones para la inclusión educativa. Lectura fácil. Ministerio de Educación, Cultura y Deporte.

Goldbach, A. y Schuppener, S. (2016). Leichte Sprache im Kontext beruflicher Teilhabe von Menschen mit Lernschwierigkeiten. Partizipative Forschung an der Universität Leipzig. En A. Hinz, T. Kinne, R. Kruschel y S. Winter, S. (eds.), Von der Zukunft her denken. Inklusive Pädagogik im Diskurs (pp. 200-209). Klinkhardt

Gutermuth, S. (2020). Leichte Sprache für alle? Eine zielgruppenorientierte Rezeptionsstudie zu Leichter und Einfacher Sprache. Frank \& Timme.

Hansen-Schirra, S. y Gutermuth, S. (2018) Modellierung und Messung Einfacher und Leichter Sprache. En S. Jekat, M. Kappus y K. Schubert (eds.), Barrieren abbauen, Sprache gestalten (pp. 7-23). ZHAW Zürcher Hochschule für Angewandte Wissenschaften.

Hansen-Schirra, S. y Maaß, C. (2020) Easy Language Research: Text and User Perspectives. Frank \& Timme.

Hansen-Schirra, S., Nitzke, J., Gutermuth, S. Maaß, C. y Rink, I. (2020). Technologies for Translation of Specialised Texts into Easy Language. En S. Hansen-Schirra y C. Maaß. Easy Language Research: Text and User Perspectives (pp. 99-127). Frank \& Timme.
IFLA, International Federation of Library Associations and Institutions (2012). Directrices para materiales de Lectura Fácil. [Traducción de Guidelines for Easyto-Read Materials, 2010]. [Archivo PDF] IFLA Professional Reports, $\mathrm{N}^{\circ} 120$. https:// www.ifla.org/files/assets/hq/publicatios professional-report/120-es.pdf

Inclusion Europe (2010). Información para todos. Las reglas europeas para hacer información fácil de leer y comprender. [Archivo PDF]. http://easy-to-read.eu/wp content/uploads/2014/12/ES_Information for all.pdf.

Jiménez Hurtado, C. y Medina Reguera, A. (en prensa). Metodología de la traducción a lectura fácil: retos de investigación. En M Estévez Grossi y P. Castillo, Translation Mediation and Accessibility for Linguistic Minorities (TRANSÜD. Arbeiten zu Theorie und Praxis des Übersetzens und Dolmetschens). Frank \& Timme.

Larraz Istúriz, C., (2015). Accesibilidad Cognitiva. CEAPAT - IMSERSO www. ceapat.es/InterPresent2/groups/imserso/ documents/binario/reto_diez_acc_cog.pdf

León, J. A., Jastrzebska, O. y MartínezHuertas, J. Á. (2018). Informe del Proyecto "Escalas de competencia lectora en la Comunidad de Madrid" ¿Cómo comprendemos lo que leemos? Plena Inclusión. https://www.plenainclusion. org/sites/default/files/plena inclusion informe investigacion_escalas_de comprension.pdf

Maaß, C. (2015). Leichte Sprache. Das Regelbuch. Barrierefreie Kommunikation 1. LIT Verlag.

Maaß, C. (2019). Übersetzen in Leichte Sprache. En Maaß, C. y Rink, Isabel (eds.), Handbuch Barrierefreie Kommunikation (pp. 273-302). Frank \& Timme.

Maaß, C. (2020). Easy Language - plain language - easy language plus: balancing comprehensibility and acceptability. Frank \& Timme. http://dx.doi.org/10.26530/20.50 $0.12657 / 42089$

Maaß, C. y Rink, I. (eds.) (2019). Handbuch Barrierefreie Kommunikation. Frank \& Timme. http://dx.doi.org/10.26530/20.500.1 2657/43216

Matamala, A. (2019). Accesibilitat i traducción audiovisual. Eumo.
Observatorio Estatal de la Discapacidad. (2016). La Accesibilidad Cognitiva en España. Estado de la situación. [Archivo PDF]. https://www. observatoriodeladiscapacidad.info/laaccesibilidad-cognitiva-en-espana-estadode-situacion/

Ocampo Gonzáles, A. A. (2015). Fácil lectura y enseñanza del español como L2: una cuestión de derechos. En A. A. Ocampo González (coord.), Lectura para todos. El aporte de la fácil lectura como vía para la equiparación de oportunidades (pp. 183233). Asociación Española de Comprensión Lectora.

Perego, E. (2020). Accessible Communication: A Cross-Country Journey. Frank \& Timme.

Pérez Gallardo, L. y Pereira Pérez, J. (2021). Las sentencias de lectura fácil como expresión de la accesibilidad cognitiva. En M. García Mayo, G. Cerdeira y L. B. Pérez Gallardo (eds.), Un nuevo derecho para las personas con discapacidad (pp. 287-304). Olejnik.

Rivero Contreras, M. y Saldaña Sage, D. (2020). ¿Legibilidad es sinónimo de comprensión en Lectura Fácil?: Una revisión de estudios sobre comprensión lectora en textos adaptados o simplificados y su calidad metodológica. En A. E. Díez Mediavilla y R. Gutiérrez Fresneda (eds.), Lectura y dificultades lectoras en el siglo XXI (pp. 714-728). Octaedro.

Seibel, C. y Carlucci, L. (2021). El lenguaje controlado: punto de partida hacia la Lectura fácil. Hikma, 20(2), 331-357.

Tavares Sánchez-Monge, G. (2016). Efectos de simplificación de textos en la comprensión lectora de las personas con discapacidad intelectual. [Tesis de doctorado no publicada]. Universitat de València.

Toribio Camuñas, S. (2020). Lenguaje simplificado en la elaboración de material accesible: un estudio de corpus. [Trabajo fin de Grado no publicado]. Universidad de Granada.

Vived, E. y Molina, S. (2012). Lectura fácil $y$ comprensión lectora en personas con discapacidad intelectual. Prensas de la Universidad de Zaragoza. 